\title{
Cervical Carcinoma Antigen: Distribution in Neoplastic Lesions of the Uterine Cervix and Comparison to Other Tumor Markers
}

\author{
Andrew Flint, M.D., * J. Philip McCoy, Jr., Ph.D., ${ }^{*}$ William J. Schade, \\ B.S., ${ }^{*}$ David A. Hofheinz, Ph.D. $\dagger$ and Harold G. Haines, Ph.D. $\ddagger$ \\ *Department of Pathology, University of Michigan School of Medicine, Ann Arbor, Michigan \\ 48104-0054; Houlter Corporation, Hialeah, Florida; \$Department of Obstetrics and \\ Gynecology, University of Miami School of Medicine, Miami, Florida
}

Received December 30, 1986

\begin{abstract}
Four antibodies (anti-CCA, anti-CEA, Ca-l, and anti-EMA) were used to study the distribution of antibody-binding sites in normal endocervical mucosa, metaplastic squamous epithelium, squamous epithelium exhibiting varying grades of intraepithelial neoplasia, and invasive squamous cell carcinoma. Anti-CCA, a novel monoclonal antibody raised against an extract of squamous cell carcinoma of the cervix, recognizes dysplastic, neoplastic, and metaplastic cervical epithelial cells. While anti-CCA and Ca-l rarely stained normal glandular epithelium, 31.4 and $45.7 \%$ of the samples stained positively for CEA and EMA, respectively. There did not appear to be significant differences between anti-CCA and the other antibodies in the frequency with which neoplastic conditions were stained. Based upon these observations, it appears that none of the antibodies tested can be regarded as a specific tumor marker. Co 1988 Academic Press, Inc.
\end{abstract}

\section{INTRODUCTION}

The identification and characterization of tumor-associated antigens which may facilitate the immunologic identification of preneoplastic and neoplastic cells of the uterine cervix have been intensively pursued over the last several years [16]. As a result, a variety of monoclonal and polyclonal antibodies have been produced which recognize several antigens reported to be present in squamous cancer cells of the uterine cervix [1-14]. Detection of epithelial membrane antigen (EMA), carcinoembryonic antigen (CEA), TA-4 antigen, the Ca antigen, and an antigen expressed on the basal cell layer of human skin and other epithelia (VM2) have received the most recent attention $[1,3,8,10,11]$. While McGee et al. [15] and others have suggested that the detection of these antigens may be of value in identifying neoplastic changes in cervical biopsy and cytology samples, there are conflicting data regarding whether some of these markers are uniformly present in preneoplastic lesions [16,17].

Employing a panel of antibodies including a monoclonal antibody raised against an extract of squamous cell carcinoma of the cervix (anti-CCA [7]), we describe 
in this report the immunoperoxidase-staining patterns of normal endocervical glandular epithelium, squamous metaplasia, and intraepithelial neoplastic conditions. Our goal was to compare this monoclonal antibody to those already in use and to determine whether this antibody panel could distinguish between these various cervical lesions.

\section{MATERIALS AND METHODS}

Tissue samples. Tissues were selected from colposcopic biopsy samples submitted for pathologic examination at Womens' Hospital, The University of Michigan. These specimens were fixed in $10 \%$ Formalin and embedded in paraffin. Biopsy samples which demonstrated either normal endocervical epithelium, squamous metaplasia, invasive squamous carcinoma, or cervical intraepithelial neoplasia (Grades 1-3) were selected for study. The samples were selected on the basis of their hematoxylin and eosin-stained appearance. The intraepithelial neoplastic lesions were evaluated and classified according to the criteria of Richart [18]. Additional histologic sections for immunoperoxidase staining were prepared.

Antisera. Monoclonal antibodies to cervical carcinoma antigen (CCA) were produced using conventional hybridoma methodology [19]. Briefly, Balb/C mice were immunized with homogenates of human cervical squamous cell carcinomas. Splenic lymphocytes from the hyperimmune mice were fused with SP2/0 cells (a nonsecreting plasmacytoma line). The appropriate hybridoma was selected by growth of the clone in selective (HAT) medium and by screening the culture supernatant for reactivity against normal and carcinomatous cervical tissue by immunofluorescence. One clone (14-3) was thus chosen for its ability to selectively stain cervical carcinoma tissue.

Murine monoclonal antibodies against epithelial membrane antigen and $\mathrm{Ca}$ antigen were obtained from Dako (anti-EMA, Santa Barbara, CA) and Wellcome Diagnostics (Ca-l, Greenville, NC), respectively. A polyclonal rabbit antibody against carcinoembryonic antigen was also obtained from Dako.

Immunoperoxidase staining. Immunoperoxidase staining was performed according to the method of Hsu et al. [20] using commercially available avidin biotin complex (ABC) kits (Vectastain, Vector Labs, Burlingame, CA). Endogenous peroxidase was removed from the sections using a methanol- $\mathrm{H}_{2} \mathrm{O}_{2}$ solution and all antibody staining was visualized using diaminobenzidine as the chromogen. Hematoxylin was used as a counterstain. The negative control for the staining with anti-CEA consisted of substitution of the primary rabbit antiserum by normal rabbit serum. As a negative control for the monoclonal antibody staining, a murine monoclonal control for the monoclonal antibody staining, a murine monoclonal of matched isotype but directed against an irrelevant antigen was used. Specificities of the antibodies were confirmed by testing the antibodies against control tissues with known positivity to the respective antigens and against normal tissues not bearing the antigen.

The immunoperoxidase-stained slides were reviewed and the cells graded for intensity of staining on an arbitrary scale from negative ( 0 ) to strongly positive $(4+)$. The staining reactions of normal endocervical glandular epithelium were also recorded. When the results were tabulated, samples containing $2+, 3+$, 


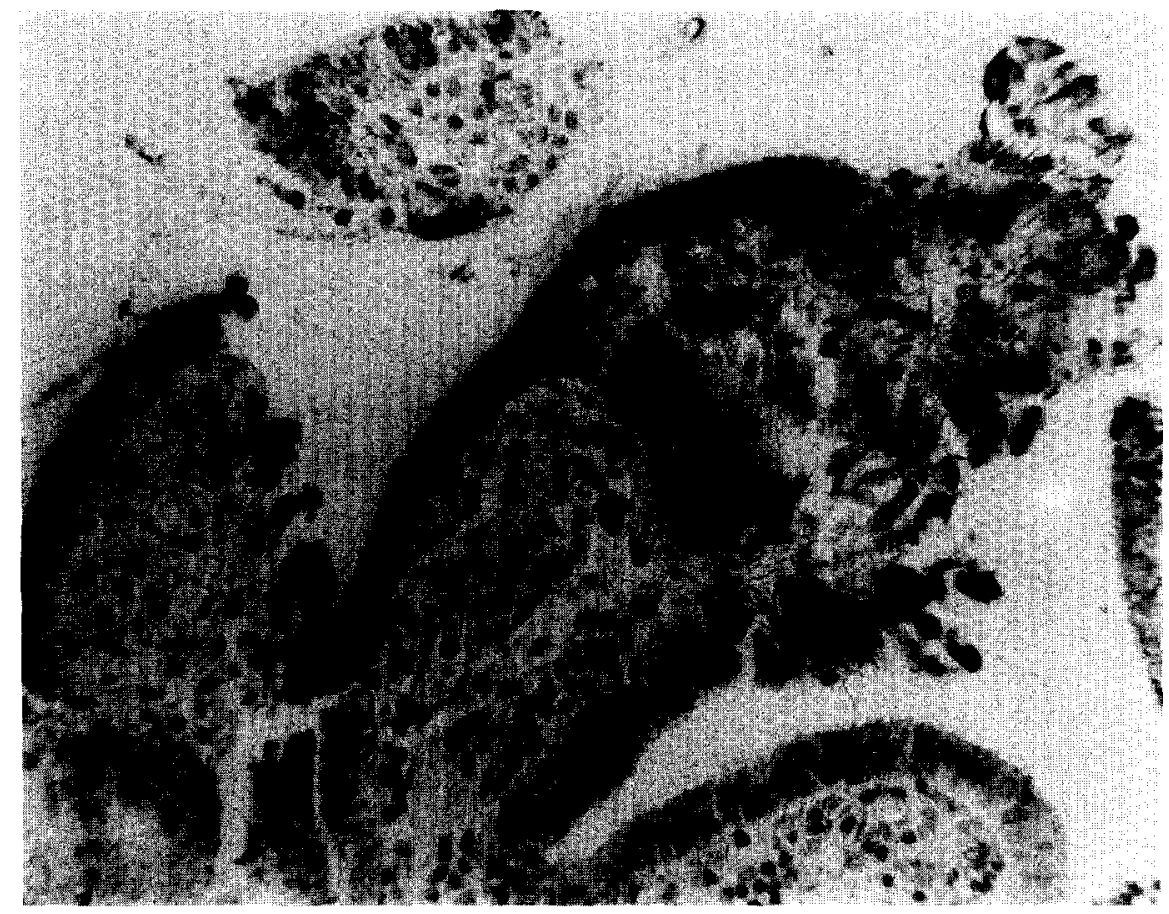

FIG. 1. Endocervical epithelium. Most of the cpithelium stains intensely for EMA. Pcroxidase staining, $\times 80$.

and $4+$ cells were classified as having strong staining, those with $1+$ cells as having weak staining, and those with no positive cells (0) as negative. Staining of parakeratotic surfaces was ignored as this staining pattern has been reported as possibly due to nonspecific absorption of antibodies [5].

\section{RESULTS}

\section{Glandular Epithelium}

Thirty-five biopsy samples contained histologically normal endocervical epithelium. This epithelium stained positively for CCA in only 1 sample. A similar result was obtained with $\mathrm{Ca}-1$ staining. In contrast, 31.4 and $45.7 \%$ of the samples stained positively for CEA and EMA, respectively. The staining was irregular, as some glands were negative for staining in otherwise positive specimens (Fig. 1).

\section{Metaplastic Epithelium}

Nine specimens contained metaplastic squamous epithelium. While the majority of specimens were positive for each of the antigens, the proportion of positive samples varied from $77.7 \%$ for CEA, to $44.4 \%$ for CCA, and to $33.3 \%$ for Ca1 and EMA. In most cases the cells stained uniformly and intensely (Fig. 2). 


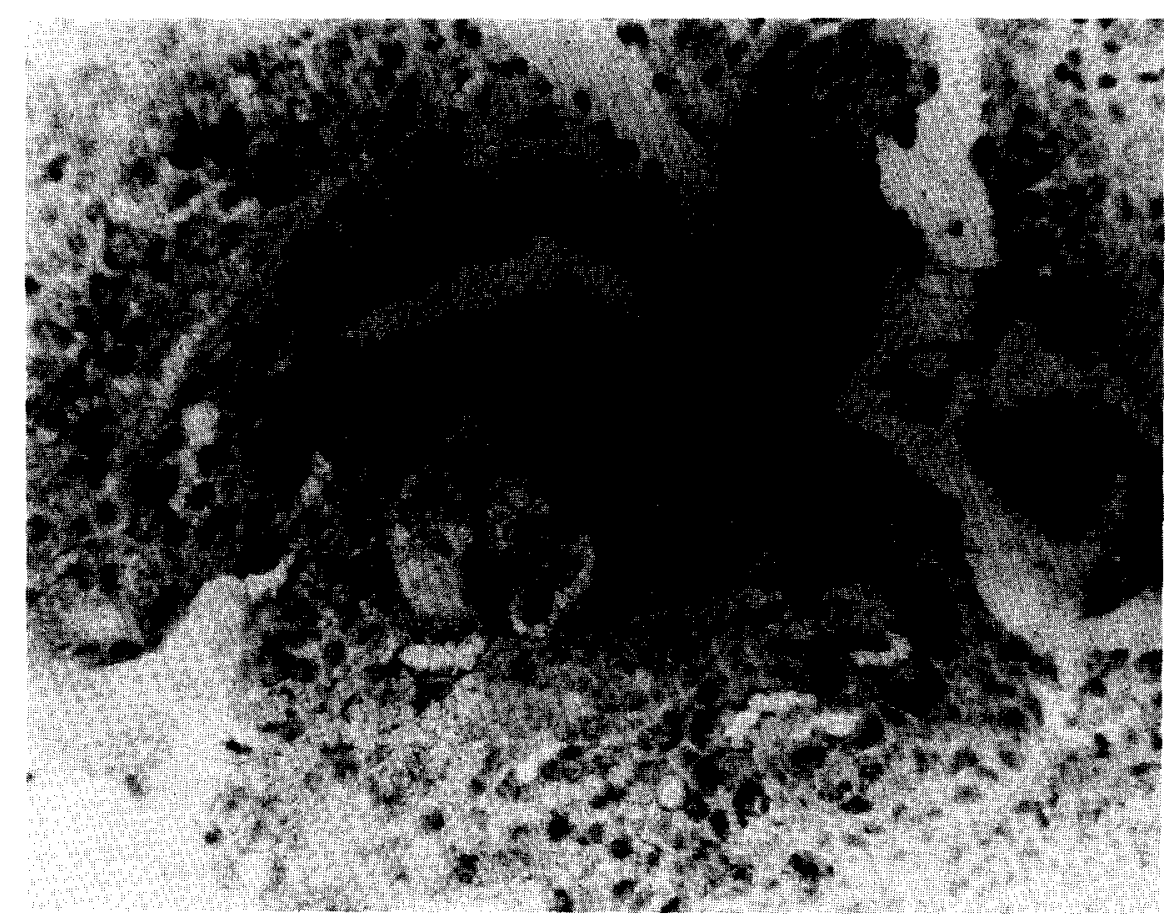

FIG. 2. Squamous metaplasia. Many of the metaplastic cells stain positively for EMA. Peroxidase staining, $\times 80$.

\section{Cervical Intraepithelial Neoplasia (CIN)}

Of the 26 samples which demonstrated varying grades of CIN ( 3 cases of CIN $1 ; 16$ cases of CIN 2; 7 cases of CIN 3), staining was positive for CEA in all of the cases. The staining was usually intense regardless of the degree of abnormality. Not all of the cytologically abnormal cells stained positively; those cells located near the mucosal surface were more often positive than those cells situated near the underlying basement membrane (Fig. 3). Similar findings obtained with the other antigens: 4 of the samples ( 3 cases of CIN 2 and 1 case of CIN 3) did not stain positively for Ca-1, 3 samples did not stain for EMA (1 case of CIN 1, 2 cases of CIN 2), and 2 samples did not stain for CCA (1 case of CIN 1 and 1 case of CIN 3).

\section{Invasive Squamous Cell Carcinoma}

The four samples containing invasive carcinoma were positive for CEA and CCA. One of the invasive carcinomas did not stain with either EMA or Ca-1. Positive staining in each sample not only varied in intensity but was also patchy, irregardless of the antibody employed.

The results of individual antibody staining are given in Table 1. 


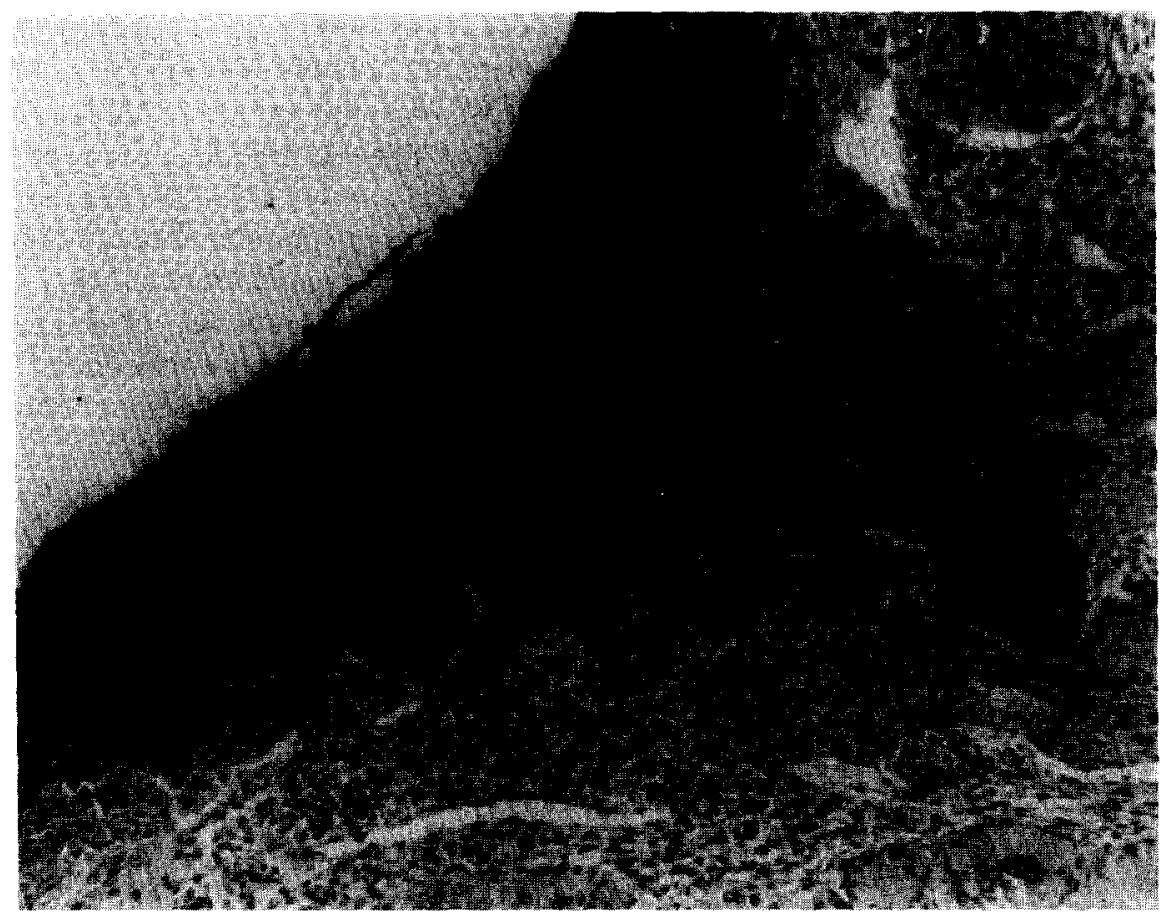

Fig. 3. Cervical intraepithelial neoplasia, grade 3. The abnormal epithelial cells stain intensely for CCA. As was often the case, the epithelial cells near the basement membrane and underlying stroma stained negatively. Peroxidase staining, $\times 80$.

\section{DISCUSSION}

The recent development of polyclonal and monoclonal antibodies have provided a new approach to the detection of cell surface and circulating tumor-specific antigens. CEA has been demonstrated in a high percentage of cases of cervical intraepithelial neoplasia [13,12]. In addition, Lindgren and associates [17] have

TABLE 1

Staining Reactions of Different Lesions

\begin{tabular}{|c|c|c|c|c|c|c|c|c|}
\hline \multirow[b]{2}{*}{ Lesion } & \multicolumn{2}{|c|}{ CEA } & \multicolumn{2}{|c|}{$\mathrm{Ca}-1$} & \multicolumn{2}{|c|}{ EMA } & \multicolumn{2}{|c|}{$\mathrm{CCA}$} \\
\hline & Pos. & Neg. & Pos. & Neg. & Pos. & Neg. & Pos. & Neg. \\
\hline Glandular epithelium & 11 & 24 & 1 & 34 & 16 & 19 & 1 & 34 \\
\hline Squamous & & & & & & & & \\
\hline metaplasia & 7 & 2 & 3 & 6 & 3 & 6 & 4 & 5 \\
\hline CIN 1 & 3 & 0 & 3 & 0 & 2 & 1 & 2 & 1 \\
\hline $\mathrm{CIN} 2$ & 16 & 0 & 13 & 3 & 14 & 2 & 16 & 0 \\
\hline CIN 3 & 7 & 0 & 6 & 1 & 7 & 0 & 6 & 1 \\
\hline Invasive cancer & 4 & 0 & 3 & 1 & 3 & 1 & 4 & 0 \\
\hline
\end{tabular}


reported a direct correlation between the frequency of tissue CEA positivity and the histologic degree of severity of cervical neoplastic lesions. These results have prompted McDicken and Rainey [5] to suggest that the presence of CEA in dysplastic epithelium is associated with definite neoplastic transformation of the epithelial cells. The EMA glycoprotein is widely distributed in epithelial tissues and tumors [22]. Although EMA is expressed by abnormal cervical epithelial cells in a consistent fashion [23], metaplastic squamous cells from normal and abnormal cervices also express the EMA antigen [11]. Expression of the $\mathrm{Ca}-1$ antigen was initially thought to be limited to malignant cervical epithelium [15]. However, subsequent investigation has demonstrated expression of $\mathrm{Ca}-1$ antigen in cytologically normal cervical epithelium as well [1].

With these studies as a background, we have attempted to distinguish between normal endocervical cells, benign metaplastic squamous cells, and cells from intraepithelial neoplastic conditions of the cervix by using a panel of four antibodies which recognize different antigens. In addition to using antibodies to the CEA, EMA, and $\mathrm{Ca}$ antigens, we employed a monoclonal antibody which reacts with dysplastic and malignant cervical epithelial cells, as well as with some metaplastic and inflammatory cells. No reactivity has been observed with normal or virusinfected cells, although reactivity has been noted with tumors arising at other sites in the body $[7,24]$.

Although the number of samples of the benign, preneoplastic, and neoplastic conditions was small, there does not appear to be a significant difference between anti-CCA and the other antibodies with regard to the frequency of antigen expression. However, anti-CCA and Ca-1 rarely stained normal glandular epithelium (only 1 of 35 samples in each case), as compared with the antibodies to CEA and EMA. The intensity and distribution of staining for the CEA, EMA, and $\mathrm{Ca}$ antigens was similar to that reported by other investigators $[1,2,5,11,14]$. The staining was often focal and mainly limited in the intraepithelial neoplastic lesions to the superficial and middle epithelial layers. With particular regard to EMA, our staining results (most intense staining in the superficial cells and weak staining in the deeper layers) is similar to those reported by Sloane et al. [21] and Moncrieff and her colleagues [11]. The relatively high frequency (31.6\%) with which normal endocervical glandular epithelium was stained by anti-CEA is at variance with the results of other studies $[5,12]$ in which CEA was not detected in normal glandular epithelia. This discrepancy may be due to the presence in this epithelia of a CEA-like substance, nonspecific cross-reacting antigen (NCA) [5], which may have been recognized by the CEA antibody used in our study.

Our observations indicate that it is not yet possible to use only a combination of antibodies to differentiate between benign conditions and neoplastic lesions of the cervix, and that none of the antibodies tested can be used as a specific tumor marker. Jha et al. [2] and Fray and colleagues [14] have reached similar conclusions based on their experience using other combinations of antibodies. This lack of specificity may have several explanations, including the possibility that the binding of antibodies to surface antigens may depend to some degree on the particular stage of the cell cycle in which the cells are found $[9,25]$. EMA, for example, appears to be expressed in benign, but proliferating cervical epithelial 
repair cells [11]. If this postulate is correct, the correlation of tumor-associated antigen cxpression and cell cycle activity may serve as a more effective approach to differentiating benign from malignant cervical cells. To this end, flow cytometric techniques have been developed [26] and are currently being employed to test this postulate.

\section{REFERENCES}

1. Lloyd, J. M., O'Dowd, T., Driver, M., and Tee, D. E. H. Immunohistochemical detection of $\mathrm{CA}$ antigen in normal, dysplastic, and neoplastic squamous epithelia of the human uterine cervix, J. Clin. Pathol. 37, 14-19 (1984).

2. Jha, R. S., Wickenden, C., Anderson, M. C., and Coleman, D. V. Monoclonal antibodies for the histopathological diagnosis of cervical neoplasia, Brit. J. Obstet. Gynecol. 91, 483-488 (1984).

3. Harlozinska, A., Kula, J., Stepinska, B., Jelen, M., Richter, R., and Slesak, B. Cervical antigen, carcinoembryonic antigen (CEA), and nonspecific cross-reacting antigen (NCA) in appraisal of uterine cervical smears., Amer. J. Clin. Pathol. 83, 301-307 (1985).

4. Bardawil, W. A. Immunocytochemical localization of carcinocmbryonic antigen (CEA), alphafetoprotein (AFP), and human chorionic gonadotropin (HCG) in cervical neoplasia, Amer. $J$. Clin. Pathol. 79, 414-420 (1983).

5. McDicken, I. W., and Rainey, M. The immunohistological demonstration of carcinoembryonic antigen in intra-epithelial and invasive squamous carcinoma of the cervix, Histopathology 7 , 475-485 (1983).

6. McCoy, J. P., and Haines, H. G. The antigenicity and immunology of human cervical squamous cell carcinoma: A review, Amer. J. Obstet. Gynecol. 140, 329-336 (1981).

7. Haines, H. G., McCoy, J. P., Hofheinz, D. E., Ng, A. B. P., Nordqvist, S. R. B., and Leif, R. C. Cervical carcinoma antigens in the diagnosis of human squamous cell carcinoma of the cervix, J. Natl. Cancer Inst. 66, 465-474 (1981).

8. Suehiro, Y., Kato, H., Michihiro, N., and Torigoe, T. Flow cytometric analysis of tumor antigen TA-4 in cervical cytologic specimens, Cancer 57, 1380-1384 (1986).

9. Koprowska, I., Zipfel, S., Ross, A. H., and Herlyn, M. Monoclonal antibodies that recognize antigens associated with human cervical carcinoma, Acta Cytol. 30, 207-213 (1986).

10. Morhenn, V. B., Schreiber, A. B., Soriero, O., McMillan, W., and Allison, A. C. A monoclonal antibody against basal cells of human epidermis: Potential use in the diagnusis of cervical neoplasia, J. Clin. Invest. 76, 1978-1983 (1985).

11. Moncrieff, D., Ormerod, M. G., and Coleman, D. V. Immunocytochemical staining of cervical smears for the diagnosis of cervical intracpithclial neoplasia, Anal. Quant. Cytol. 6, 201-205 (1984).

12. Bychkov, V., Rothman, M., and Bardawil, W. A. Immunocytochemical localization of carcinoembryonic antigen (CEA), alpha-fetoprotein (AFP), and human chorionic gonadotropin (HCG) in cervical neoplasia, Amer. J. Clin. Pathol. 79, 414-420 (1983).

13. Hurlimann, J., and Gloor, E. Adenocarcinoma in situ and invasive adenocarcinoma of the uterine cervix: An immunohistologic study with antibodies specific for several epithelial markers, Cancer 54, 103-109 (1984).

14. Fray, R. E., Husain, O. A. N., To, A. C. W., Watts, K. C., Lader, S., Rogers, G. T., TaylorPapadimitriou, J., and Morris, N. F. The value of immunohistochemical markers in the diagnosis of cervical neoplasia, Brit. J. Obstet. Gynecol. 91, 1037-1041 (1984).

15. McGee, J. O. D., Woods, C. J., Ashall, F., Bramwell, M. E., and Harris, H. A new marker for human cancer cells. II. Immunohistochemical detection of the $\mathrm{Ca}$ antigen in human tissues with the Cal antibody, Lancet 2, 7-I0 (1982).

16. Goldenberg, D. M., Sharkey, R. M., and Primus, F. J. Carcinoembryonic antigen in histopathology: Immunoperoxidase staining of conventional tissues, $J$. Natl. Cancer Inst. 57, 11-22 (1976).

17. Lindgren, J., Walstrom, T., and Seppala, M. Tissue CEA in premalignant cpithclial lesions and epidermoid carcinoma of the uterine cervix: Prognostic significance, Int. J. Cancer 23, 448453 (1979). 
18. Richart, R. M. Cervical intraepithelial neoplasia, Pathol. Annu. 8, 301-363 (1973).

19. Kohler, G., and Milstein, C. Continuous cultures of fused cells secreting antibody of predefined specificity, Nature (London) 256, 495-497 (1975).

20. Hsu, S. M., Raine, L., and Fanger, H. The use of avidin-biotin peroxidase complex (ABC) in immunoperoxidase technique: a comparison between $\mathrm{ABC}$ and unlabled antibody (PAP) procedures, J. Histochem. Cytochem. 29, 577-580 (1981).

21. Sloane, J. P., Ormerod, M. G., Carter, R. L., Gusterson, B. A., and Foster, C. S. An immunocytochemical study of the distribution of epithelial membrane antigen in normal and disordered squarnous epithelia, Diag. Histopathol. 5, 11-17 (1982).

22. Sincock, A., Middleton, J., and Moncrieff, D. Towards an automated procedure for the quantitative cytological screening of cervical neoplasms, J. Clin. Pathol. 36, 535-538 (1983).

23. Moncrieff, D., Ormerod, M. G., and Coleman, D. V. Tumor marker studies of cervical smears: Potential for automation, Acta Cytol. 28, 407-410 (1984).

24. Hofheinz, D. E. Monoclonal antibodies to cervical carcinoma antigens. Dissertation, University of Miami, Coral Gables, FI, pp. 1-137 (1983).

25. Czerniak, B., Darzynkiewicz, Z., Staino-Coico, L., Herz, F., and Koss, L. G. Expression of $\mathrm{Ca}$ antigen in relation to cell cycle in cultured human tumor cells, Cancer Res. 44, 4342-4346 (1984).

26. Flint, A., McCoy, J. P., Jr., Esch, T. R., Beckwith, A. L., and Morley, G. W. Simultaneous measurement of DNA content and detection of surface antigens of cervical vaginal cells by flow cytometry, Anal. Quant. Cytol. Histol. 9, 419-424 (1987). 